\title{
Why Social Acceptance in South African Solar Water Heater Projects Should Shape National Energy Policy: The Case of Bluegumbosch
}

\author{
Dr Geoffrey Mukwada
}

Senior Lecturer, Department of Geography, University of the Free State, Private Bag X13, Phuthaditjhaba 9866, South Africa

Email: gmukwada@gmail.com

\section{Dr Wisemen Chingombe}

Postdoctoral Research Fellow, Department of Geography, University of the Free State, Private Bag X13, Phuthaditjhaba 9866, South Africa

Email:wchingombe@gmail.com

Dr Phillip Taru

Postdoctoral Research Fellow, Department of Geography, University of the Free State, Private Bag X13, Phuthaditjhaba 9866, South Africa Email: philiptaru@yahoo.ie

\section{Doi:10.5901/mjss.2014.v5n16p635}

\section{Abstract}

This paper investigates the key determinants of the social acceptance of the Solar Water Heater project in Bluegumbosh, a South African rural community that is situated in a former homeland. Data was collected through a questionnaire survey and interviews that were conducted with officials from the Department of Energy, ESKOM and the local municipality, as well as the beneficiaries of the project. Data from the questionnaire survey was analyzed statistically, using the Statistical Package for the Social Sciences (SPSS). The results indicate that while the level of social acceptance for the project is high, its potential to increase is threatened by a number of barriers which include environmental problems, poor workmanship, low level of the project's capacity to generate employment, poor complaints handling, as well as poor participation by the local community. The paper concludes that ideally, these barriers should be replaced with social acceptance satisfiers in order to reduce poverty and enhance the livelihoods of Solar Water Heater project beneficiaries.

Keywords: livelihood portfolios, poverty reduction, renewable energy, social acceptance barriers, social acceptance satisfiers

\section{Introduction}

All over the world, increasing the share of renewable energy is high on the policy agenda of countries (Wustenhagen, 2007). Solar energy has emerged as a leading alternative to grid-based rural electrification in many developing countries (Jacobson, 2006). In recent years, considerable attention has been given to solar heating and photovoltaic (PV) electricity as an alternative to grid sourced electricity (Mulugetta et al., 2000). This initiative has created significant environmental benefits in these countries (Tsoutsos et al, 2005). At the same time, the financial resources of the poor, who constitute the majority in these countries, are already stretched due to the expenses they incur towards improved energy services, particularly for the power they require for conveniences such as electric lighting, TV and radio. In BRICS member states, especially in China, India and South Africa, renewable energy sources are increasingly becoming the mainstay of the economy (Yuan et al, 2011; Ramachandra et al, 2011; Wlokas, 2011). In China, energy consumption from renewable energy resources will account for between 10\% and 15\% of total energy consumption between 2010 and 2020 (Yuan et al, 2011). With plans underway to quadruple the GDP by 2020, against the 2000 benchmark (Chung-Ling Chien and Lior, 2011) reliance on renewable energy sources is expected to escalate. The projected economic growth will lead to a soaring of demand for energy. In order to sustain the projected rapid economic growth, BRICS member states have to increase the share of renewable energy sources such as geothermal, wind and solar energy, either due to shortage of energy or due to environmental concerns. In South Africa, Africa's biggest economy, plans are underway to install a 
million Solar Water Heaters (SWHs) by 2014 (Peters, 2009), to curb energy deficits created by escalating demand, while simultaneously addressing challenges of greenhouse gas emissions, unemployment and poverty (Afrane-Okese, 2009; Wlokas, 2011). In the rural areas of South Africa, the majority of the poor people are women, who are also usually the major users and suppliers of energy resources in marginalized communities (Cecelski, 2000). Despite their need for energy for lighting, cooking, mechanical power, heating, cooling, and communication, most poor people in rural areas do not have adequate access to liquid fuels and electricity. It is therefore necessary to evaluate solar projects since solar energy is likely to become the major zero fuel alternative source on which the materially poor majority will depend in future.

Cecelski (2000) maintains that in South Africa, the constraints that energy poverty imposes on the country's development strategy are still invisible in the mainstream development debate. Regarding this issue, two salient features could emerge in future debates on the developmental role of solar energy. First, the view that solar technology can benefit the poor is not necessarily incontrovertible. Often, solar energy production is considered as "low tech" and is assumed to have the capacity to readily diffuse into poor communities who are quick and ready to adopt it. Second, but closely connected to the first point, is the view that being small scale, solar technology is affordable and easy to manage, and therefore its use is sustainable. However, research conducted hitherto has not yielded conclusive results on this issue. What is apparent is that social acceptance can act as a sieve or filter in the diffusion of solar energy technology. It is within the context of this reality that the social acceptance of "small-scale" solar projects has to be carefully assessed. While the importance of social acceptance has been researched in renewable energy in general and the PV industry in particular, gaps still exist in what is known about how it relates to the success of SWH projects in South Africa. This is partly because generally social acceptance is part of renewable energy technology implementation that has largely been neglected in the past (Wustenhagen et al., 2007). The dearth of research on SWH projects in South Africa has been highlighted by Wlokas (2011: 27) who maintains that though reports have been compiled on technical and financial aspects of SWH projects information about the social benefits of SWH installed in residential areas is not readily available while "the impact of solar water heaters on people's livelihoods, their energy use and their behaviour regarding water consumption remains largely unexplored."

The objective of this study is therefore to investigate the conditions that regulate the social acceptance of the Bluegumbosch (BGB) SWH project in order to empirical evidence that could to inform the national renewable policy in South Africa and other emerging economies.

\section{Literature Review}

There are numerous criteria for evaluating the success of renewable energy projects. These include energy market conformity, investment certainty, competitiveness and governance (de Jager et al., 2011), as well as environmental and social criteria (Klessmann et al., 2011). In China (Chung-Ling Chien and Lior, 2011), Indonesia (Miller et al., 2012) and India (Ramachandra et al., 2011), considerable attention is already being given to sustainable projects designed to meet, not only technical and economic criteria but also environmental and social criteria at grassroots level. Energy sources should be accepted socially to reduce cost, emission, and use of petroleum products and to promote use of local energy sources (Jinturkar and Deshmukh, 2013). Accordingly, Miller et al. (2012) note that when evaluating renewable energy generation technology options, several considerations must be taken into account, including available energy resources, potential impacts of a technology or mix of technologies on the grid (when grid connected), life cycle costs, technology maturity, ongoing maintenance requirements and local expertise, and social and environmental considerations. We can argue further that these considerations underpin the social acceptance of renewable energy projects. Such considerations should, however, take into account the micro-economic impacts of various applications and approaches. Balancing economic, social, and environmental conditions is central to achieving sustainable development (Chung-Ling Chien and Lior, 2011). "The transition to a sustainable development can thereby be arranged under consideration of social and economic compatibility aspects" (Stocker et al, 2011: 6083). Elsewhere, previous research has established that social acceptance plays a critical role in the success of renewable energy projects (Coenraads et al., 2008; Miller et al., 2012). For instance, Miller et al. (2012) note that in the US, social acceptance can be an issue in the case of wind turbines or large photo voltaic (PV) farms being located in view sheds, on previously undisturbed areas, or near culturally significant sites. In Austria, the expansion of hydropower is limited due to environmental and social acceptance constraints, while lacking social acceptance restricts the further exploitation of wind power in areas of high potential (Stocker et al., 2011). Similarly, in Turkey, administrative hurdles, obstacles to grid access, lack of information and training and social acceptance are the non-economic barriers that the country should overcome in order to increase renewable energy supply (Tükenmez and Demireli, 2012). It is therefore clear that while solar resource potential, techno- 
economic feasibility and organizational aspects play an indispensable role, social acceptance gives the "final verdict" on the long term success of solar power generation (Ramachandra et al., 2011). Social acceptance is what makes development projects compatible with communities. It is the "social license" that any technological innovation requires for its adoption and diffusion.

Potential social acceptance is one of the criteria that have been factored into the designs of renewable energy projects (Cosentino et al., 2012). In some instances, social acceptance is induced by material poverty. The experience of those living in fuel poverty has to be tied in to the larger economic and social conditions of present times (Jenkins et al., 2011). Energy-poor households often require additional infrastructure, including installation of energy-saving measures. The user-acceptance of technology is important and is directly linked to the social status and needs of any household. In this regard, part of the social responsibility of developers, a crucial issue in development projects, is to ensure that social acceptance is given sufficient attention when the projects are implemented. Social acceptance, together with issues such as administrative hurdles, lack of information and training are some of the issues that make it necessary to embed incentive support in renewable energy policies (IEA, 2008; UNEP, 2011).

In India, incentives on renewable energy production have led to improvement of livelihoods. For instance, in the Sundarbans region in West Bengal and the Sagar Dweep island there is evidence suggesting that decentralized solar electrification has led to improvement in education, income generation, social life and health among locals (Ramachanra et al, 2011). Social acceptance can also be triggered by health related benefits. In China, SWH projects have increased the availability and use of hot water for laundry and dish washing, leading the reduction of prevalence of rheumatoid arthritis (Han et al., 2010), as well as respiratory disorders and the risks associated with fuel and electricity usage such as paraffin poisoning, burns, fires, and electric shocks, and improvement of indoor air quality (Wloks, 2011).

In Africa, where the potential for developing renewable energy is huge (but largely unexploited), enhancement of social acceptance of renewable energy projects could augment poverty reduction efforts. In Tunisia and South Africa, for instance, incentives that promote social acceptance could boost further production of solar energy production. Both countries have policies that support SWH projects. In the case of Tunisia, long-term efforts and investment subsidies and consumer loans managed and guaranteed by the state-owned utility have enhanced growth rates in the SWH market by more than 25\% in recent years (UNEP, 2011). As for South Africa, direct financial incentives based on energy output or capacity could boost renewable energy production, as opposed to the current system where incentives are based on a percentage of installation costs which merely encourages oversized installations (NEP, 2011). Each of the above cited cases implies that if properly implemented, renewable energy projects can serve as a development tool. In this case, social acceptance is linked to the benefits that are derived from the projects or the social value that the beneficiaries attach to the projects. It is interesting to note that in all the cases cited above, incentives are at the root of social acceptance.

Under these circumstances, it can be argued further that in developing countries, the social acceptance of a solar project is determined by the perceived outputs of the project. The Global Environment Facility (GEF) funded project in Zimbabwe illustrates this point. The GEF is a financial mechanism that provides grants and concessional funds to developing countries for projects and activities that tackle environmental challenges which have global implications. This is because the majority of the people who live in the rural communities of most developing countries are materially poor. The GEF is jointly implemented by the United Nations Development Programme (UNDP), the United Nations Environment Programme (UNEP) and the World Bank (Mulugetta, 2000). In the case of Zimbabwe, the major benefit for households in a SWH pilot project was financial (Batidzirai, 2009), particularly due to the direct impact it had on beneficiary households. Consequently, the GEF funded solar project was readily accepted because of the developmental role that it played in rural communities. There is a strong case to argue therefore that the social acceptance of a project is a reflection of the social compatibility between the project and the values that are inherent to the community in which the project is implemented, as well as the bricolage of livelihood portfolios prevailing in that community. Social acceptance therefore denotes the extent to which a project blends and resonates with the needs of the host community. We can conclude therefore that social acceptance is a major determinant of the sustainability of any development project.

Another important conclusion that can be drawn about the GEF solar project in Zimbabwe is that poverty, which serves as the pretext and motivation for adopting solar energy projects, is actually a constraint that inhibits the implementation of the project. The components that are required to produce solar energy, including solar panels, and thermal heating accessories are often beyond the reach of many rural communities, as demonstrated in the research that was conducted in GEF funded projects in Kenya and Zimbabwe (Mulugetta, 2000; Jacobson, 2006). This suggests that the sustainability of solar energy projects is not determined by size alone, but also by the pricing of the electricity generation unit (Evans et al., 2009) and the other components that are required in the functionality of the technology. Under the above circumstances, evaluating pro-poor solar energy projects, remains a hugely relevant undertaking and 
will contribute to the growing body of literature relating to the application of renewable energy technologies in rural areas. Moreover, from the foregoing discussion the assessment of social acceptance must be given attention in policy making.

\section{Study Area}

The BGB SWH project was recently founded in the Maluti-a-Phofung (M-a-P) local municipality, in QwaQwa, a former homeland that was established during the apartheid era for the Sotho speaking people. The area is located in the eastern Free State and is characterized by high levels of unemployment and widespread poverty. M-a-P is one of the poorest municipalities in South Africa. The BGB community consists of two wards, namely Ward 32 and Ward 34 . Ward 32 comprises the more recently built Disaster Park and Snake Park residential areas, while Ward 34 mainly consists of Phase 1, the oldest part of the BGB area. In the last decade, the development priorities of the M-a-P have been centred on provision of basic infrastructure, including water reticulation, road construction and paving, storm water channelling, as well as services such as health, education, sewerage systems, sporting facilities, housing and electricity supply. Between 2003 and 2011 the municipality extended the electricity grid and connected a total of 2392 households to the national grid. Due to poverty, many of the households struggle to meet their demand for electricity, making it necessary to explore alternative energy sources.

The main objective of setting up the SWH project was to save electricity while improving the livelihoods of the project beneficiaries. The project was funded by the Department of Energy (DoE), but managed by South Africa's power utility ESKOM. It was envisaged that the amount of energy saved would amount to $4.72 \mathrm{GWh}$ per annum. Upon its completion in July 2012, the project comprised 6,475 solar water heaters that were installed mainly in houses that were built through the Reconstruction and Development Programme (RDP), 3,302 of which were installed by JV KEAP and another 3,173 by Clean Heat. RDP houses were targeted because of their firm walls and roof structures, comprising mainly of brick and corrugated iron sheets, respectively. Originally the project was meant to benefit communities in Vryburg. However, due to water quality related problems experienced in that town, a decision was taken to transfer the project to BGB. This suggests that no careful planning was done prior to the implementation of the project. Accordingly, the project has never been an integral component of the current Integrated Development Plan of the municipality.

\section{Methodology}

A household questionnaire survey was conducted in BGB in order to establish the factors that influence the social acceptance of the SWH project. The targeted respondents were household heads. A total of 364 households (considered to be sufficient at the $95 \%$ Confidence Level and Confidence Interval of 5\%) were randomly sampled using computer generated random number tables to establish the benefits of the SWH project, problems associated with it, purposes for which water from the SWHs is used, frequency and preference of use, level of participation of the beneficiaries of the project, as well as the development priorities of the beneficiaries. As part of the research, interviews were held with officials from the DoE, ESKOM (the electricity supply utility), Maluti-a-Phofung Municipality and the local ward councillor, to corroborate the data from the questionnaire survey. The data from the questionnaire survey was analysed statistically using SPSS.

\section{Results}

The results of this study indicate that the majority of the residents of BGB have benefited from the SWH project. As shown in Table 1, about $93.7 \%$ of the respondents either agreed or strongly agreed that the project has been beneficial to their households, denoting high social acceptance. Similarly, $95.9 \%$ of the household heads who responded to the questionnaire indicated that the SWH project has improved the livelihood of their households. This scenario is not surprising considering that the majority of the households are poor. 
Table 1. Responses on the extent to which the BGB residents agree that the SWH project has been beneficial to their households.

\begin{tabular}{|l|c|c|}
\hline \multicolumn{1}{|c|}{ Response } & Frequency & Percentage \\
\hline Strongly agree & 329 & 90.7 \\
\hline Agree & 12 & 3.3 \\
\hline Neutral/ Indifferent & 13 & 3.6 \\
\hline Disagree & 6 & 1.6 \\
\hline Strongly agree & 4 & 1.1 \\
\hline \multicolumn{1}{|c|}{ Total } & 364 & 100.0 \\
\hline
\end{tabular}

Figure 1 shows that the majority of the households in BGB earn less than R2 $000^{1}$ per month, while only a small minority earn more than R10 000 per month. This is due to the fact that most of the households are headed by poorly educated individuals who can only occupy low paying jobs. About $91.5 \%$ of the household heads in the BGB area hold a Matric certificate or a lower qualification, and are thus unable to hold high salary jobs or professional positions. Without a subsidy from the DoE, many of them would be unable to afford the SWHs, which are generally priced around R 8000 per unit.

A total of $343(94.2 \%)$ households in BGB use the water every day, suggesting that the SWH project is of huge importance to them. The percentages of households that use water from the SWHs for different purposes are shown in Figure 1, while Figure 2 demonstrates the frequency of use among daily water users. It can be argued that in BGB the water from the SWHs is a critical component of household chores, as well as the bricolage of livelihood portfolios of the local community.

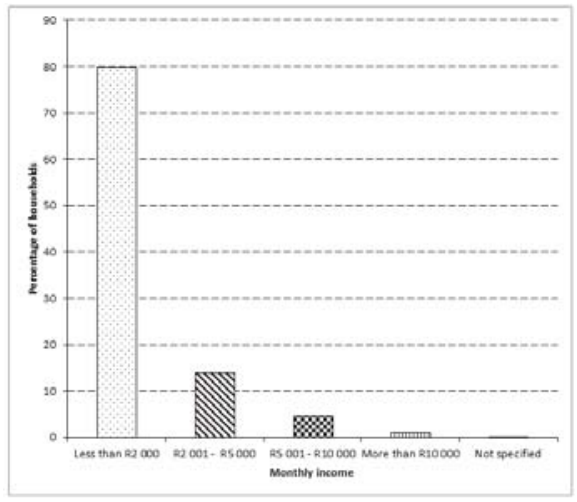

Figure 1. Average monthly household income earned by the BGB community

Interviews with officials from ESKOM confirmed that the SWH project has reduced the consumption of electricity in the BGB community, showing that the objective of the project to shift the community towards zero-fuel renewable heat options has partly been achieved. However, there are a number of factors that contribute positively or negatively towards the social acceptance of the project. These are social acceptance satisfiers (SASs) and social acceptance barriers (SABs), respectively, as discussed below. While SASs are satisfaction enhancers, SABs are satisfaction suppressors.

\subsection{Social Acceptance Satisfiers (SASs)}

SASs are closely connected to the benefits of the project. Table 2 presents the benefits that households in BGB derive from the SWH project, as well as the number and percentages of those who have benefited. As shown in Table 2, reduced energy consumption and reduced expenditure on electricity are considered by many households as major benefits, demonstrating that economic factors pose the greatest influence on social acceptance. Perceived reduction of fire related hazards and accidents, as well as household convenience and the potential of the SWH to contribute to a cleaner home environment, have also contributed significantly to the social acceptance of the project, though to a lesser

${ }^{1}$ As at 10 May 2013, one rand was equivalent to approximately US $\$ 0.11$ 
degree. These conditions are the major satisfiers that make the project attractive to the residents of the BGB community. However, SASs are also linked to the purpose to which the water from SWHs is used (Figure 2).

Table 2. Benefits of the SWH project

\begin{tabular}{|c|c|c|}
\hline Benefits of the project & Number of respondents & Percentage of total \\
\hline \multicolumn{3}{|l|}{ Financial benefits } \\
\hline It saves energy & 129 & 35.4 \\
\hline It has lowered electricity bills & 259 & 71.2 \\
\hline It has reduced expenditure on paraffin & 14 & 3.8 \\
\hline It has lowered expenditure on coal & 6 & 1.6 \\
\hline $\begin{array}{l}\text { Family members were employed during installation or are employed in carrying out } \\
\text { installations or maintenance work }\end{array}$ & 2 & 0.5 \\
\hline \multicolumn{3}{|l|}{ Social and Health Related benefits } \\
\hline It has reduced power cuts & 19 & 5.2 \\
\hline It reduced fire related hazards and accidents & 34 & 9.3 \\
\hline It reduced electric shocks & 8 & 2.2 \\
\hline Health & 1 & 0.3 \\
\hline \multicolumn{3}{|l|}{ Environmental and health related benefits } \\
\hline It has improved indoor air quality & 13 & 3.6 \\
\hline It has made the home environment cleaner & 31 & 8.5 \\
\hline $\begin{array}{l}\text { It has reduced environmental pollution (reference to the broader environmental } \\
\text { issues such as greenhouse gases etc.) }\end{array}$ & 10 & 2.7 \\
\hline \multicolumn{3}{|l|}{ Other benefits } \\
\hline Saves time & 26 & 7.1 \\
\hline Convenience & 70 & 19.2 \\
\hline
\end{tabular}

\subsubsection{Reduced Energy Bills}

As noted in Table 2, the vast majority of the households in the BGB community (76.6\%) believe that the SWH project has contributed positively to their livelihoods by lowering household energy bills, especially electricity bills. Some households indicated that their electricity bills have been more than halved.

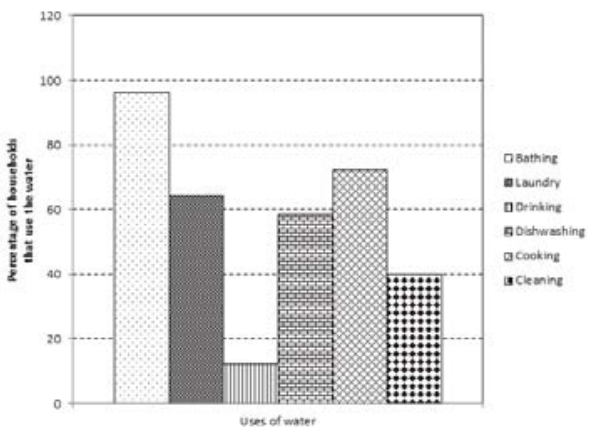

Figure 2. Use of water from the solar water heaters in BGB area.

On average each household spends about R200 on electricity every month. The money saved as a result of reliance on the SWHs can now be used to meet other important household needs, such as food, education, health and other necessities. About $94.2 \%$ of the households use water from the solar water heaters on a daily basis, largely for the purposes specified in Figure 3. 


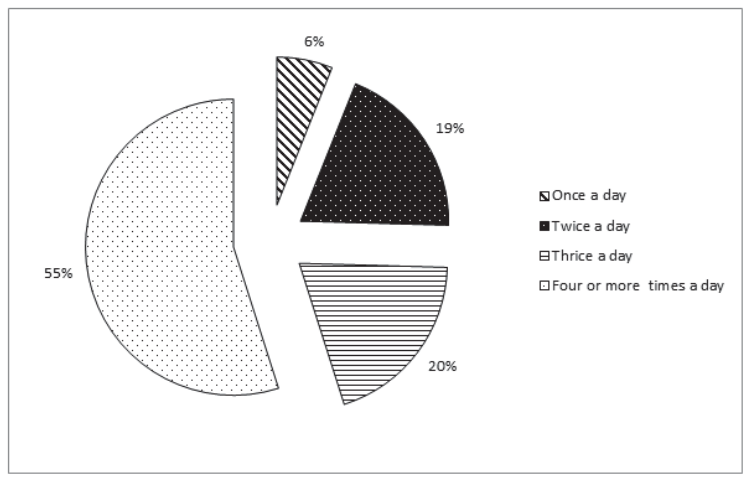

Figure 3. Proportion of households which use water from the solar water heaters on a daily basis.

\subsubsection{Convenience, Time Saving and Water Uses}

Convenience was cited by the members of the BGB community as one of the benefits of the SWH project. As many as 70 (19.2\%) of the household heads who responded to the questionnaire survey indicated that they now enjoy greater convenience with respect to access to warm or hot water. For instance, before the solar water heaters were installed the residents used to endure the cumbersome routine of heating bath water using electric kettles. This problem particularly affected large households because considerable amount of time and energy were expended daily. A total of 26 (7.1\%) of the households indicated that the installation of SWHs has reduced the amount of time they require to prepare themselves for work or to prepare their children for school in the morning. Hot or warm water is now readily available, almost on daily basis, even on those days when tap water is not available. The solar water heater tanks serve as reservoirs from which water can be drawn at all times. It was for this reason that some residents suggested that the tanks should be replaced with larger ones.

\subsubsection{Environmental Safety}

While the financial savings that are derived from the project are important, as noted above, environmental and safety conditions also contribute significantly to the SASs. The most notable environmental issues are hygienic in nature, including the role that SWHs play in creating a cleaner and a less polluted home environment (Table 2). Similarly, the BGB community residents (9.3\%) noted that fire related hazards and accidents, including electric shocks, have been reduced as a result of increased reliance on water from the SWHs.

However, some complaints have been raised about the project. Most of these complaints are linked to poor workmanship on the part of the contractors who installed the SWHs. The majority of the complaints relate to the problems that were reported about the project, some of which have since been rectified. Nevertheless, as noted below, a larger share of these problems has not yet been addressed, including those linked to defective heaters. While a reporting system has already been set up to enable the project beneficiaries to report defects or malfunctioning SWHs, the system has not been effective due to reasons elucidated below.

\subsection{Social Acceptance Barriers (SABS)}

We use the term SABs to describe the conditions that suppress social acceptance. Many of these conditions are linked to the design of the project rather than its purpose. About $57(15.7 \%)$ of the households reported that the roofs of their houses are now leaking due to the holes that were drilled during installation. Also, 130 (35.7\%) respondents reported that the SWHs that were installed at their homesteads are either not working or defective. The ratio of the number of other problems that were reported to the total number of households is 0.22 , which is fairly high. Many of the dysfunctional problems that were reported resulted from poor workmanship. 


\subsubsection{Environmental Threats}

The BGB community cited a number of environmental threats associated with the SWH project. These relate to the acoustic design and locational aspect of the SWHs and prevailing weather conditions.

\subsubsection{Acoustic design}

Residents from the BGB community complained about the rattling sound that emanates from the SWH. When the water boils the iron roofing sheets on which the solar water heaters were mounted generates some vibrations, thus causing noise.

\subsubsection{Locational aspect}

Due to incorrect orientation, some solar heaters are hardly directly exposed to insolation. This problem is most serious in winter, especially where the heaters were installed on south facing gables. Poorly located heaters are hardly exposed to optimum insolation levels during winter, leading to poor SWH performance.

\subsubsection{Weather variability}

Variable weather changes were cited as a major cause of poor SWH performance. During winter, and also on cloudy days, the performance of the solar water heaters is below optimum. In winter, this problem is worsened by the accumulation of snow on rooftops. Snowing increases the albedo of the roof and reduces heat absorption, rendering the heaters less effective. Also, in winter when temperatures fall, water freezes in the pipes, causing pipe blockages, thus preventing the warm water from flowing through, in some cases even leading to the rapturing of the pipes. This is because water has the tendency to expand when it freezes. This problem is worsened by unreliable water supply. The times when water is available do not always coincide with the times when insolation is greatest. Another weather related environmental hazard that threatens the long-term viability of project is hailstorms. Hailstorms are common in the eastern Free State region and are a potential cause of damage to the glass tubing through which solar energy is absorbed by the heaters.

\subsubsection{Hygienic factors}

One of the most important environmental factors that undermine the social acceptance of the project is that at most homesteads the water from the solar water heaters can only be accessed from the toilet. Consequently, the majority of the residents consider the water as unsuitable for cooking or drinking because they regard it as a health hazard.

\subsubsection{Structural Defects, Structural Damages and Property Losses}

Apart from environmental threats there are a number of factors that exert an influence on SABs, most of which arise from the defects of the SWHs or how they were installed. These factors are discussed below.

\subsubsection{Defective SWHs and structural problems}

Besides the fact that the houses in BGB were not initially designed to accommodate SWHs, many of the heaters that were installed proved to be mechanically and functionally defective. A total of 880 heaters that were installed by one of the two companies that were involved in the project were malfunctioning and operationally deficient. Cases were reported where the pipes that lead water from the heater's tank were either leaking or blocked altogether. One of the major causes of blockages was the type of adhesive that was used to seal the pipes, which has the propensity to melt when subjected to high temperatures, particularly when the tank is empty. Once melted, the adhesive flows and sets or coagulates in the pipes, thus sealing the pipes and preventing water from flowing completely.

The overflow pipe through which water escapes from the tank when the water is overheated is considered to be a defect by some residents. This is because it can contribute to an enormous loss of water if the heater is not frequently emptied. On the other hand the frequent emptying of the heater leads to wastage of water and soaring of water bills. Another structural defect relates to the pipes that lead water from the heater's tank to where the water is used. Some 
residents complained that the water is not directed to the places where it is most required, since this water is only accessed through the toilet or the kitchen. Also, some residents preferred the water pipes to be fitted outside their houses instead of running along the interior walls where they are a potential cause of dampness, in the event of leakage, even though this could expose the water to greater chances of freezing in winter. Nevertheless, there are some residents who felt that the water pipes are a nuisance because they spoil the interior decor of their houses.

\subsubsection{Structural damages and property losses}

A serious problem that was reported by the residents relates to the structural damages and property losses that took place during installation. Often the compensation that the owners of the damaged property received was meagre and way below the market value of the property. This created animosity between the installers and the beneficiary community. A case in point is where one resident was paid only R150.00 as compensation of a R2 000 worth of dressing table that was damaged by the installers. Furthermore, claims took long to be processed, while those who made attempts to follow up were often ridiculed or treated rudely. Some household heads who were interviewed indicated that they were asked by the installers to pull down part of the ceiling from their houses in order to make way for water pipes but were never compensated for the damage. In some cases the leakage of pipes discolours the walls and cause dampness in the house.

\subsubsection{Skills Development and Employment Generation}

The BGB SWH project did not generate any significant job or skills development opportunities for the local community. Of the seventy four people who were hired to install the SWHs, only six were recruited from the BGB community. Forty-eight of the installers were recruited from elsewhere in QwaQwa, while twenty were from outside QwaQwa. The project was therefore viewed as not socially responsive by the members of the local community. Only these few residents were lucky to receive training in installing the SWHs. Worse still, only two members of the local community were trained to maintain the heaters but were, interestingly, not provided with equipment to repair defective heaters. The installers received a three day training, which did not sufficiently equip them with technical skills to maintain the heaters. About $80.5 \%$ of the residents indicated that they did not have the skills required to service the heaters. The failure to implement a more robust skills training programme left a skills gap in the community. Some residents referred to cases where they had to hire artisans at their own personal expense to repair the heaters, usually at exorbitant costs. Another case showing lack of social responsiveness relates to an accident where an installer fell off a ladder while mounting a SWH, only to receive a four week wage of R2000 as compensation.

\subsubsection{Participation and Complaints Handling}

About $94.2 \%$ of the households indicated that they did not directly participate in the design and implementation of the SWH project, even though they were the beneficiaries. Only $5.8 \%$ stated that they actively participated in decision making during the implementation of the project. This means that the views of the majority of the community members were grossly overlooked, suggesting that a top-down approach was adopted in the implementation of the project. However, as shown in Table 3, some residents noted that they participated indirectly, even though they are a small minority. Only $1.4 \%$ of the residents believed that they were in charge of the decisions that were made when the project was implemented. This minority is politically connected to the African National Congress, the ruling party. 
Table 3. Level of Participation in the BGB SWH Project

\begin{tabular}{|l|c|c|}
\hline Questionnaire responses related to level of participation & Number of respondents & Percentage of total \\
\hline $\begin{array}{l}\text { Representatives were chosen from our community but they did not make } \\
\text { decisions }\end{array}$ & 29 & 8.0 \\
\hline $\begin{array}{l}\text { Tasks were assigned to us or our representatives but decisions were made } \\
\text { by those who installed the heaters }\end{array}$ & 40 & 1.1 \\
\hline $\begin{array}{l}\text { Our opinions were sought but decisions were made by those who installed } \\
\text { the heaters }\end{array}$ & 52 & 14.3 \\
\hline $\begin{array}{l}\text { We worked together with those who installed the heaters but decisions were } \\
\text { made by those who did the installation }\end{array}$ & 3 & 0.8 \\
\hline $\begin{array}{l}\text { We shared knowledge on the solar water heaters and we worked together } \\
\text { with those who installed the heaters }\end{array}$ & 5 & 1.4 \\
\hline $\begin{array}{l}\text { We are the ones who made decisions and we only invited those who } \\
\text { installed the heaters to work with us }\end{array}$ & 5 & 36.6 \\
\hline \multicolumn{1}{|c|}{ Total } & 133 & \\
\hline
\end{tabular}

When asked if they were aware of the existence of any complaint handling procedures that they could follow in the event that the heaters that were installed at their homesteads were defective, about $56 \%$ of the household heads indicated that they were not aware of the procedures or the procedures did not exist. This suggests that the majority of the residents are not benefiting from any after service care for the project. Neither of the two installing companies left personnel to address SWH related problems, even though some of the heaters have never worked from the beginning. Complaints were left to the Community Liaison Officer (CLO), who was temporarily employed by the municipality to report on the progress of the project. While the CLO reports directly to the local councillor and acts as a conduit of complaints between the local community and the municipality, attempts to bring back the two companies to rectify SWH defects have been fruitless.

\subsubsection{Nefarious Activities and Underhand Related Issues}

On paper, information was available regarding the number of heaters that were installed but it was not possible to verify the actual number of heaters that were installed in BGB. This is because the number of heaters did not correspond with the number of houses, especially in Snake Park, where houses that should have received heaters have not yet been constructed. Also, in Snake Park, some houses have more than one stand number. Furthermore, cases were also reported where one of the contracted companies requested residents to sign documents confirming that heaters had been installed at their homesteads, when in fact the heaters had been installed by a different company. A report was also made of five residents who removed installed heaters, and another case where a heater went missing altogether. Some of the heaters that were dismounted were relocated to sites other than those for which they were originally intended, including an industrial site in Phuthaditjhaba, a nearby town.

\section{Discussion}

As indicated by the results of this research, the huge proportion of households that acknowledged benefiting from the SWH project depicts a high level of social acceptance for the project. However, the foregoing discussion confirms that social acceptance is a complex phenomenon that is driven by a matrix of antagonistic forces, including SASs and SABs. While SASs enhance satisfaction and promote social acceptance, SABs constitute a countervailing force that undermines it. Judging from the responses of the BGB residents in the questionnaire survey it appears that the influence of SASs by far outweighs the influence of SABs. The most important satisfiers are related to the financial benefits that are directly derived from the project, particularly by reduced expenditure on electricity. Reduced electricity bills has had an immediate and direct impact on most materially poor households, for whom savings readily translate into opportunities for meeting important household needs such as education, health and food.

Argued from this angle, findings from the BGB SWH project mirror those from a GEF funded SWH pilot project that was implemented in Zimbabwe, which showed that financial benefits that had a direct impact on beneficiary households constituted the major benefits of the project (Batidzirai, 2009). This view is resonant with Jenkins' et al. (2011) argument that social acceptance is influenced by the larger economic and social conditions that prevail in an area. This proves that it is necessary to embed financial incentives in renewable energy projects (IEA, 2008; UNEP, 2011). However, as shown in the preceding sections of this paper, in the case of the BGB SWH project, social conditions are regulated by SASs and 
SABs. SASs include conditions such as convenience, time budgets, environmental and safety conditions, while SABs relate to the influence that environmental conditions that affect the performance of the solar heaters, structural design, property damages and losses, perceptions about corruption, inadequate complaints handling procedures, as well as poor levels of community participation. In order to enhance the social acceptance of SWH projects, these conditions must be factored into the designs and implementation of renewable energy projects because of the role they play in determining levels of social acceptance. In this context, findings from this research land weight to Miller's (2012) argument that ongoing maintenance requirements, local expertise, social and environmental conditions should be taken into consideration when evaluating renewable energy policies and generation technology options. In BGB there is evidence of mismatch between housing design and SWH installation. SWHs were introduced long after the houses had been built and the acoustic and locational aspects of the heaters were not factored into the designs. Illuminating research that was recently conducted in China by Yuan et al. (2011) revealed that problems can arise where the installation of SWHs is not taken into consideration during the design of houses.

The social acceptance of the BGB SWH project can be enhanced through training. As shown above, a lack of after care service and skills development programmes undermined the performance of the project. Such a situation is similar to experiences which were reported in Turkey, where administrative hurdles, lack of information and training are found to be barriers that the country has to overcome in order to increase renewable energy supply (Tükenmez and Demireli, 2012). In the case of BGB this situation was worsened by the fact that most residents were not aware of complaint handling procedures and the majority had no information about who to report to about defective heaters. Thus it can be argued that apart from enhancing SASs and minimizing SABs, the national renewable energy policy in South Africa should place emphasis on the provision of after care services and skills development so that renewable energy development programmes become more sustainable and effective in promoting rural development.

\section{Conclusion}

The objective of this study was to identify the conditions that affect the level of social acceptance of the BGB SWH project in order to determine the extent to which they affect the viability of the project. From the foregoing discussion, it has been shown that these conditions fall into two categories, namely SASs and SABs, that is satisfaction enhancers and satisfaction suppressors, respectively. It can be argued and concluded that the promotion of the former by means of financial incentives can increase social acceptance in SWH projects. Similarly, social acceptance can also be enhanced by eliminating the latter. The financial incentives accorded by SWH projects should have a direct positive impact on the livelihoods of project beneficiaries. It can be concluded therefore, that these incentives must have the capacity to not only to create opportunities to save money but also to broaden opportunities for creating new jobs, generate power, develop new skills and enable the beneficiaries to participate in all stages solar energy technology development. This knowledge is important for designing zero-fuel renewable heat policy options for domestic use in developing countries, where renewable energy sources such as solar energy is the hope of the majority, who are materially poor. However, while this research has shown that financial gains are one of the main driving forces behind social acceptance, future research on the social acceptance of renewable energy projects should investigate the level of participation in decision making among project beneficiaries. This will help to determine the extent to which the decisions that are made in these projects are in line with the priorities of beneficiary communities. It is this aspect that makes social acceptance important in shaping national policy on SWH projects.

\section{References}

Afrane-Okese, Y. (2009). Draft Strategic Framework \& Implementation Plan For South African National Solar Water Heating, Overall Recommended High Level Strategic Framework, presented at the National Solar Water Heating Conference. 'Building Consensus on Accelerating the Rollout of Solar Water Heaters in South Africa. Johannesburg, South Africa.

Batidzirai, B., Lysen, E.H., Egmond, S., \& van Sark, W.G.J.H.M., (2009). Potential for solar water heating in Zimbabwe. Renewables and Sustainable Energy Reviews, 13(3), 567-582.

Cecelsk, E. (2000). Enabling equitable access to rural electrification: Current thinking and major activities in energy, poverty and gender. Briefing Paper prepared for a Brainstorming Meeting on Asia Alternative Energy Policy and Project Development Support: Emphasis on Poverty Alleviation and Women Asia Alternative Energy Unit, The World Bank, Washington, DC, 26-27 January 2000.

Chung-LingChien, J. \& Lior, N. (2011). Concentrating solar thermal power as a viable alternative in China's electricity supply, Energy Policy, 39, 7622-7636.

Coenraads, R., Reece, G., Voogt, M., Ragwitz, M., Held, A., Resch, G., Faber, T., Haas, R., Konstantinaviciute, I., Krivo`sík, J., Chadim, 
T., 2008. PROGRESS_Promotion andGrowthofRenewableEnergySourcesandSys- tems. FinalReport.TREN/D1/422005/S07.56988.Utrecht. http://ec.europa. eu/energy/renewables/studies/doc/renewables/2008_03_progress.pdfS (December 10, 2012)

Cosentino, V., Favuzza, S., Graditi, G., Ippolito, M.G., Massaro, F., Sanseverino, E.R. \& Zizzo, G. (2012). Smart renewable generation for an islanded system: Technical and economic issues of future scenarios. Energy, 39, 196 -204.

De Jager, D., Klessmann, C., Stricker, E., Winkel, T., de Visser, E., Koper, M., Ragwitz, M., Held, A., Resch, G., Busch, S., Panzer, C., Gazzo, A., Roulleau, T., Gousseland, P., Henriet, M., \& Bouille', A. (2011). Financing Renewable Energy in the European Energy Market. By order of the European Commission, DG Energy, TREN/D1/ 518-2008. Utrecht: Ecofys.

Evans, A., Strezov, V., \& Evans, T.J. (2009). Assessment of sustainability indicators for renewable energy technologies, Renewable and Sustainable Energy Reviews, 13, 1082-1088.

Han, J. M., Mol, A.P.J., \& Lu, Y. (2010). Solar water heaters in China: A new day dawning. Energy Policy, 38(1), 383-391.

Hestnes, A.G. (2000). Building integration of solar energy systems. Solar Energy, 67 (4-6), 181-187.

International Energy Agency (IEA), (2008). Deploying Renewables: Principles for Effective Policies, Paris: OECD/IEA.

Jenkins, D., Middlemiss, L., \& Pharoah, R. (2011). A study of fuel poverty and low carbon synergies in social housing. Edinburg: Urban Energy Research Group

Jinturkar, A.M., \& Deshmukh, S.S. (2013). Sustainable development by rural energy resources allocation in India: A fuzzy goal programming approach. International Journal of Energy Optimization and Engineering, 2(1), 37-49.

Klessmann, C., Held, A., Rathmann, M., \& Ragwitz, M. (2011). Status and perspectives of renewable energy policy and deployment in the European Union-What is needed to reach the 2020 targets? Energy Policy, 39, 7637-7657.

Miller, M., Voss, P., Warren, A., Baring-Gould, I. \& Conrad, M. (2012). Strategies for International Cooperation in Support of Energy Development in Pacific Island Nations. National Renewable Energy Laboratory (NREL) Technical Report. http://www.ntis.gov/help/ordermethods.aspx (April 10, 2014)

Mulugetta, Y., Nhete, T., \& Jackson, T. (2000). Photovoltaics in Zimbabwe: lessons from the GEF solar project. Energy Policy, 28, 10691080.

Ramachandra, T.V., Jain, R., \& Krishnadas, G. (2011). Hotspots of solar potential in India. Renewable and Sustainable Energy Reviews, $15,3178-3186$.

Stocker, A., Großmann, A., Madlener, R., \& Wolter, M.I. (2011). Sustainable energy development in Austria until 2020: Insights from applying the integrated model "e3.at". Energy Policy, 39, 6082-6099.

Tsoutsos, T., Frantzeskaki, N., \& Gekas, V. (2005). Environmental impacts from the solar energy technologies. Energy Policy, 33, 289296.

Tükenmez, M., \& Demireli, E. (2012). Renewable energy policy in Turkey with the new legal regulations. Renewable Energy, 39, 1-9.

UNEP. (2011). Difussion of renewable energy technologies: Case studies of enabling frameworks in developing countries. Roskilde: UNEP Riso Centre on Energy.

Wlokas, H.L. (2011). What contribution does the installation of solar water heaters make towards the alleviation of energy poverty in South Africa? Journal of Energy in Southern Africa, 22 (2), 27-39.

Wustenhagen, R., Wolsink, M. \& Burer, J. (2007). Social acceptance of renewable energy innovation: An introduction to the concept. Energy Policy, 35, 2683-2691.

Yuan, X., Zuo, J. \& Ma, C. (2011). Social acceptance of solar energy technologies in China-End users' perspective. Energy Policy, 39, $1031-1036$ 